\title{
sciendo

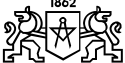

\section{Optimization of the Effective Heat Supply Radius for the District Heating Systems}

\author{
Valery STENNIKOV ${ }^{1}$, Ekaterina MEDNIKOVA ${ }^{2}$, Ivan POSTNIKOV ${ }^{3 *}$, \\ Andrey PENKOVSKII ${ }^{4}$ \\ ${ }^{1-4}$ Melentiev Energy Systems Institute of Siberian Branch of the Russian \\ Academy of Science (ESI SB RAS), Irkutsk, Russia
}

\begin{abstract}
The problem of determining the effective (optimal) heat supply radius is considered. Heat supply radius is transportation distance of heat energy in the district heating systems (DHS), under which the highest indices of economic efficiency of district heating to consumers are respected. To solve this difficult and multifactorial problem, a bi-level approach has been proposed. This approach allows finding the optimal frameworks of territorial areas of district heating while fulfilling the necessary requirements for thermal-hydraulic modes in heat networks and for reliability of heating to consumers. Methodology for solving the formulated problem is based on bi-level programming methods, models of Theory of hydraulic circuits, nonlinear optimization methods, nodal reliability indices (availability factor, failure-free operation probability), Markov random processes models and other methods and models. A case study has been conducted using the developed methodological apparatus for the actual DHS scheme of the Irkutsk city (Russia, Siberia).
\end{abstract}

Keywords - Connection charge; district heating system; effective heat supply radius; energy management; nodal reliability indices; optimization; reliability of heat supply; specific cost

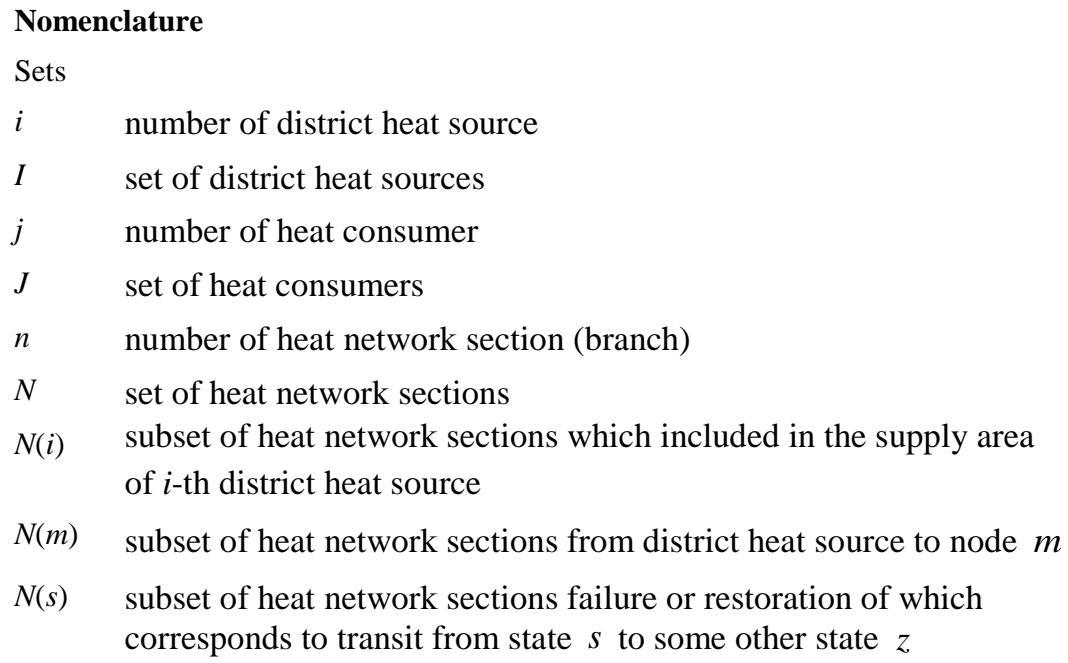

\footnotetext{
* Corresponding author.

E-mail address: postnikov@isem.irk.ru
} 


\begin{tabular}{|c|c|c|}
\hline$N(z)$ & $\begin{array}{l}\text { subset of heat network sections failure or restoration of which to } \\
\text { transit from state } z \text { to some other state } s\end{array}$ & \\
\hline$N^{\prime}(s)$ & $\begin{array}{l}\text { subset of heat network sections failure of which corresponds to transit } \\
\text { to some state } s\end{array}$ & \\
\hline$M$ & number of heat network nodes & \\
\hline$M$ & set of heat network nodes & \\
\hline$M_{\mathrm{ef}}$ & $\begin{array}{l}\text { subset of heat network nodes located in the zone of effective heat } \\
\text { supply radius }\end{array}$ & \\
\hline$s, z$ & numbers of system state & \\
\hline E & complete set of system states & \\
\hline$E(s)$ & subset of system states from which the system can transit to state $s$ & \\
\hline \multicolumn{3}{|c|}{ Functions } \\
\hline$F_{\mathrm{obj}}^{1}$ & objective function of the first level: heat supply radius & $\mathrm{m}$ \\
\hline$F_{\text {obj }}^{2}$ & $\begin{array}{l}\text { objective function of the second level: cost on production and } \\
\text { distribution of thermal energy in the system }\end{array}$ & EUR \\
\hline$R_{\mathrm{ef}}$ & effective heat supply radius & $\mathrm{m}$ \\
\hline$\varphi$ & variable coefficient depending on type of heat source & - \\
\hline $\mathrm{B}$ & average number of consumers per $1 \mathrm{~km}^{2}$ & number $/ \mathrm{km}^{2}$ \\
\hline$\Delta t$ & temperature difference of heat carrier in supply and return pipes & ${ }^{\circ} \mathrm{C}$ \\
\hline$c_{\mathrm{t}}$ & thermal capacity of the heat carrier & $\mathrm{MWh} /\left(\mathrm{t}^{\circ} \mathrm{C}\right)$ \\
\hline$\Delta H$ & $\begin{array}{l}\text { total pressure drop in the supply pipe from the heat source to the most } \\
\text { peripheral substation }\end{array}$ & $\mathrm{Pa}$ \\
\hline$l_{n}$ & length of $n$-th section of heat network & $\mathrm{m}$ \\
\hline$d_{n}$ & diameter of $n$-th heat network section & $\mathrm{m}$ \\
\hline$x_{n}$ & heat carrier flow rates in $n$-th network section & $\mathrm{t} / \mathrm{h}$ \\
\hline$k_{n}$ & specific investment cost for $n$-th heat network section (re)construction & $\mathrm{EUR} / \mathrm{m}$ \\
\hline$\psi_{n}$ & specific pressure drop in $n$-th section & $\mathrm{Pa} / \mathrm{m}$ \\
\hline$\tau_{0}$ & duration of the heating period & $\mathrm{h}$ \\
\hline$\tau_{\mathrm{p}}$ & hours of pump operation under design load & $\mathrm{h}$ \\
\hline$\tau_{s j}$ & $\begin{array}{l}\text { part of the heating period within which state } s \text { is a failed state for } \\
\text { consumer } j\end{array}$ & $\mathrm{~h}$ \\
\hline$Q_{i}^{0}$ & total (maximum) heat load of $i$-th heat source & $\mathrm{MWh} / \mathrm{h}$ \\
\hline$Q_{i}$ & connected heat load of the $i$-th district heat source & $\mathrm{MWh} / \mathrm{h}$ \\
\hline$Q_{j}$ & $\begin{array}{l}\text { heat load of the } j \text {-th consumer connected to the considered heat } \\
\text { source }\end{array}$ & $\mathrm{MWh} / \mathrm{h}$ \\
\hline$Q_{\mathrm{los}}$ & heat losses & $\mathrm{MWh} / \mathrm{h}$ \\
\hline
\end{tabular}




\begin{tabular}{|c|c|c|}
\hline$Z_{m}$ & cost on production and distribution of thermal energy in node $m$ & EUR \\
\hline$Z_{\mathrm{av}}$ & average cost on production and distribution of thermal energy in system & EUR \\
\hline$s_{h i}$ & heat production cost of the $i$-th heat source & EUR/MWh \\
\hline$s_{\mathrm{e}}$ & electricity cost & EUR/MWh \\
\hline$\alpha$ & annuity rate & \\
\hline$k_{i}$ & specific capital investment in $i$-th heat source capacity expansion & EUR/MW \\
\hline$f$ & share of heat network depreciation, repair and maintenance charges & \\
\hline$\eta_{\mathrm{p}}$ & pump efficiency & \\
\hline$p_{s}, p_{z}$ & probability of system state $s$ and $z$ respectively & \\
\hline$p_{0}$ & probability of totally operable system state & \\
\hline$k_{\mathrm{ef}}$ & connection effectiveness coefficient & \\
\hline$\varepsilon$ & $\begin{array}{l}\text { ratio of the total network length to the length of the heat transmission } \\
\text { networks }\end{array}$ & \\
\hline$l_{j}$ & $\begin{array}{l}\text { length of the designed heat network from connection point to } \\
\text { consumer } j\end{array}$ & $\mathrm{~m}$ \\
\hline$q_{L}$ & linear heat density & $\mathrm{MWh} / \mathrm{m}$ \\
\hline$L_{\mathrm{ef}}$ & $\begin{array}{l}\text { total length of heat transmission networks at boundaries of effective } \\
\text { heat supply radius }\end{array}$ & $\mathrm{m}$ \\
\hline$l_{\text {jmax }}$ & maximum connection distance for consumer $j$ & $\mathrm{~m}$ \\
\hline$Q_{j \min }$ & $\begin{array}{l}\text { minimum necessary load level of consumer } j \text { for its connection at a } \\
\text { fixed point of the heat network }\end{array}$ & MW \\
\hline \multicolumn{3}{|c|}{ Matrices and vectors } \\
\hline A & $\begin{array}{l}\text { incidence matrix with linearly independent } m \text { nodes and } n \text { sections } \\
\text { (branches) of the heat network (dimension }(m-1) \times n)\end{array}$ & \\
\hline $\mathrm{x}$ & vector of heat carrier flow rates in the network sections & $\mathrm{t} / \mathrm{h}$ \\
\hline $\mathrm{G}$ & vector of mass flow rates at nodes & $\mathrm{t} / \mathrm{h}$ \\
\hline$\overline{\mathbf{A}}^{\mathbf{T}}$ & transposed node-branch incidence matrix & \\
\hline $\mathrm{P}$ & vector of pressures at nodes & $\mathrm{Pa}$ \\
\hline h, $\mathrm{H}$ & vectors of losses and pressure heads & $\mathrm{Pa}$ \\
\hline $\mathrm{S}$ & diagonal matrix of hydraulic resistance coefficients & $\mathrm{mh}^{2} / \mathrm{t}^{2}$ \\
\hline $\mathrm{X}$ & vector of flow rates in the network sections & $\mathrm{t} / \mathrm{h}$ \\
\hline$|\mathbf{x}|$ & vector of absolute values of flow rates in the network sections & $\mathrm{t} / \mathrm{h}$ \\
\hline Q & vector of thermal energy flow rates at nodes & MW \\
\hline \multicolumn{3}{|c|}{ Reliability indices and parameters } \\
\hline$\lambda_{n}$ & failure rate of heat network sections $n$ & $1 / \mathrm{h}$ \\
\hline
\end{tabular}




\begin{tabular}{|lll|}
\hline$\mu_{n}$ & restoration rate of heat network sections $n$ & $1 / \mathrm{h}$ \\
$K_{j}$ & nodal availability factor \\
$K_{j}^{0}$ & standard value of availability factor \\
$R_{j}$ & nodal failure-free operation probability \\
$R_{j}^{0}$ & standard values of failure-free operation probability \\
\hline
\end{tabular}

\section{INTRODUCTION}

The main goal of the expansion and upgrading of district heating systems (DHS) of towns and cities is to meet the demand for heat and provide reliable heat supply at minimum economic and environmental cost. Moreover, it is also important to economically incentivize the development and adoption of energy saving technologies, and provide a system approach to the DHS designing. Optimal planning of DHS, their scale, and distance of heat transmission largely determine the efficiency of heat supply development and modernization. Rational construction of DHS based on innovative technologies and energy efficient equipment considerably reduce investment and annual operating costs, and enhance the efficiency and reliability of these systems.

In the European countries, especially in the Scandinavian countries, the active development of the DHS began after the oil crisis of 1973 [1]-[3]. In Russia, large-scale construction of district (centralized) heat sources began as part of the plan «GOERLO» in the 1970s [1], [4]. According to classification presented in [5] DHS of that time are $1^{\text {st }}$ generation systems. Currently Russian DHS mainly are second generation systems. Some large cities have $3^{\text {rd }}$ generation heating systems. In the European countries, today most DHS are $3^{\text {rd }}$ generation systems. The main goal of energy strategies of Europe and Russia is to improve energy efficiency, reliability and comfort of heat supply like it suggests $4^{\text {th }}$ generation [5], [6]. Recently many researchers are discussing the transition to intelligent energy systems [5], [7]. In the case of Russia achieving this goal is complicated not only by the large size of systems but also by its number. The construction of new $4^{\text {th }}$ generation DHS requires significant investment in upgrading equipment for both DHS and heat-consuming installations. Today consumers and heating companies are not ready to incur increased costs.

It also seems important to note the problem of sustainable energy planning in general is comprehensive and very important for a social, economic and environmental point of view [8]. For example, methods to provide the effective energy policy and legislative aspects of this problem are considered in [9]-[11].

In the current situation, problems of determining the criteria for the efficiency of connecting new consumers are of great importance to optimal development of DHS. As a rule, economic criteria are used: if the cost of heating the consumer from a centralized source is lower than from an individual source, then its connection to DHS is considered as economically feasible [12]. This problem becomes even more topical when implementation the technology of parallel consumption wherein the heat consumer connected to the DHS also consumes heat produced by other energy sources [13], [14]. Heat supply planning is usual and legislated in Europe. However, each country has its own features in the organization of heat supply. Scandinavian countries are developing municipal energy plans that include territory-zoning maps by type of heat supply or levels of heat density [15]-[19]. The Heat roadmap Europe states that DHS will be suitable in dense urban areas, while local heat pumps and biomass 
boilers will be suitable in other areas [20]-[23]. In Denmark, connection to DHS for consumers with sufficient level of heat density is obligatory. To expand the district heating area, new technologies are introducing that allow to improve energy-efficiency of heating with low heat demand. Authors [24]-[26] pay attention to pipe design methods and proposed improved methods for distribution pipes design to reduce heat losses. Economic feasibility of low temperature DHS in areas with low heat density was analyzed in [27], [28]. The issue of integration of decentralized thermal storages within DHS is discussed in [29]. Also in Sweden, economic feasibility of connection of new consumers is estimated by linear heat density and additionally by effective width for areas with detached houses [30]. In Finland, consumers have the right to choose a way of heating and the connection charge is determined by the building sizes and the location of consumer [31], [32]. The organization of heat supply in Russia and China has some similarities. Generation of heat is based on large combined heat and power plants (CHPP), Government regulation of the heat tariffs is carried out, the consumer can choose between district and individual heating. At the same time, in China since 2007, and in Russia since 2009 DHS and construction of CHPP are priorities within energy policy [33], [34].

In many considered cases and also according to the Russian law "About Heat Supply" the effectiveness of decisions made on the expansion of DHS can be assessed according to the criterion of an effective heat supply radius (EHSR) or in other words the extension of heat network from heat source to consumer. The parameter EHSR is unique and used only in Russia. European researchers use other criteria, for example, heat density and linear heat density [17], [18]. EHSR and linear heat density have similar patterns, but it's not the same. EHSR is the distance from a heat source to a node, behind which the connection of new consumers is not economically feasible. Linear heat density is a criterion, which we can use to estimate EHSR and local radius, for example. It is also important to add that development existing DHS should be rational to make it more efficient. Optimal planning, determination of EHSR and conditions of new consumers connection will help to improve current situation in Russian. We consider, that it's first and important step on the way to the main goal of energy strategy - intelligent heating systems or $4^{\text {th }}$ generation DHS. Within the framework of this area, researches related to the prosumer and the use of low-temperature modes in DHS are especially perspective [28], [35]-[37].

The search for EHSR represents an important problem for designing and development of DHS. An analysis of scientific and technical literature shows that the calculation of EHSR has been paid sufficiently great attention to, since the time of district heating emergence. The research shows that EHSR and heat source service areas depend greatly on specific features of systems and location of heat sources [38]-[41]. The studies on the determination of effective district heating zones have been recently restarted [42]-[44]. It is worth noting that the considered techniques do not take into account the reliability requirements in the calculation of EHSR, this can result in severer consequences of failures in system.

The basic principle of heat supply planning for Russia was presented in [41], [45]. At the same time, currently there is no regulatory documents to provide a technique for the calculation of EHSR. Thus, the objective of determining an optimal size of DHS requires the development of a new methodological basis, which will enable us to decide on connection of new consumers to the system, based on the calculation of EHSR. Thus, we can conclude that it is necessary to calculate the EHSR for each heat source of DHS for all directions of transmission pipelines, assess the heat supply reliability indices and, additionally, assess each new connection in zone of effective district heating according to an additional criterion - a 
local effective heat supply radius (LHSR). We propose techniques for the assessment both of EHSR for the heat transmission pipelines and LHSR.

\section{Methodology}

\subsection{General Optimization Model for Search of Effective Heat Supply Radius}

The considered problem is formulated as determine to maximum EHSR at minimum cost price on production and distribution thermal energy in DHS. Moreover, should be taken into account requirements to reliability heat supply to consumers. This optimization problem can be solved by the bi-level programming methods [46]-[48]. Thus, the considered problem is represented by the following set of expressions.

Objective functions are:

$$
\begin{gathered}
F_{\mathrm{obj}}^{1}=\sum_{n \in N(i)} l_{n} \rightarrow \max , i \in I \\
F_{\mathrm{obj}}^{2}=\sum_{i \in I}\left[\left(s_{\mathrm{h} i}+\alpha k_{i}\right)+\left(\frac{(f+\alpha) \sum_{n \in N(i)}\left(k_{n} d_{n} l_{n}\right)}{Q_{i}^{0}}+\frac{s_{\mathrm{e}} \tau_{\mathrm{p}} \sum_{n \in N(i)}\left(x_{n} \psi_{n} l_{n}\right)}{367.2 \eta_{\mathrm{p}} Q_{i}^{0}}\right)\right] \rightarrow \min .
\end{gathered}
$$

Cost for nodes of system and average cost in system are:

$$
\begin{gathered}
Z_{m}=\left(s_{\mathrm{hi}}+\alpha k_{i}\right)_{m}+\left(\frac{(f+\alpha) \sum_{n \in N(m)}\left(k_{n} d_{n} l_{n}\right)}{Q_{i}^{0}}+\frac{s_{\mathrm{e}} \tau_{\mathrm{p}} \sum_{n \in N(m)}\left(x_{n} \psi_{n} l_{n}\right)}{367.2 \eta_{\mathrm{p}} Q_{i}^{0}}\right), \\
Z_{\mathrm{av}}=\frac{1}{\sum_{i \in I} Q_{i}} \sum_{i \in I}\left[Q_{i}\left(s_{\mathrm{hi}}+\alpha k_{i}\right)+Q_{i}\left(\frac{(f+\alpha) \sum_{n \in N(i)}\left(k_{n} d_{n} l_{n}\right)}{Q_{i}^{0}}+\frac{s_{\mathrm{e}} \tau_{\mathrm{p}_{n \in N(i)}}\left(x_{n} \psi_{n} l_{n}\right)}{367.2 \eta_{\mathrm{p}} Q_{i}^{0}}\right)\right] .
\end{gathered}
$$

Thermal energy balance in the system is:

$$
\sum_{i \in I} Q_{i}=\sum_{j \in J} Q_{j}+Q_{\mathrm{los}}
$$

Flow distribution model is [49]:

$$
\begin{gathered}
\mathrm{Ax}=\mathrm{G}, \\
\overline{\mathrm{A}}^{\mathrm{T}} \mathrm{P}=\mathrm{h}-\mathrm{H}, \\
\mathrm{h}=\mathrm{SX}|\mathrm{x}|, \\
\mathrm{Q}=\mathrm{Gc}_{\mathrm{t}} \Delta \mathrm{t} .
\end{gathered}
$$


Nodal reliability indices are [50]:

$$
\begin{gathered}
K_{j}=\sum_{s \in E} p_{s}\left(\left(\tau_{0}-\tau_{s j}\right) / \tau_{0}\right), \\
R_{j}=\exp \left(-p_{0} \sum_{s \in E} \sum_{n \in N^{\prime}(s)} \tau_{s j} \lambda_{n}\right) .
\end{gathered}
$$

Markov random process of the evolution of events (failures and restorations of heat network sections) [50]-[52]:

$$
p_{s}\left(\sum_{n \in N(s)} \lambda_{n}+\sum_{n \in N(s)} \mu_{n}\right)=\sum_{z \in E(s)}\left(\sum_{n \in N(z)} p_{z} \lambda_{n}+\sum_{n \in N(z)} p_{z} \mu_{n}\right), s \in E .
$$

Constraints on variables and parameters are:

$$
\begin{gathered}
Z_{m} \leq Z_{\mathrm{av}}, m \in M_{\mathrm{ef}}, \\
Z_{m}>Z_{\mathrm{av}}, m \notin M_{\mathrm{ef}}, \\
0 \leq Q_{i} \leq Q_{i}^{0}, i \in I, \\
K_{j} \geq K_{j}^{0}, j \in J, \\
R_{j} \geq R_{j}^{0}, j \in J .
\end{gathered}
$$

The objective function of the first level (1) is maximizing of EHSR as sum of heat network sections which included in the supply area of $i$-th district heat source. The objective function of the second level (2) is minimizing of general cost on production and distribution of heat energy in the system. The numerical coefficient of 367.2 is necessary to convert expression parameters to correct dimension. Flow distribution in the heat network determine with use the thermal-hydraulic model (6)-(9) which present basic system equations of Theory of hydraulic circuits [49] and consist on the Kirchhoff laws and closing equations. Reliability of heat supply to consumers is estimated on nodal reliability indices: availability factor (10) and failure free operation probability (11). These indices determined with use equation system of Markov random process (12). In more detail the issues of applying the Markov random processes in the problems of DHS reliability are considered in [50]-[52].

Solution of formulated nonlinear problem is based on method of coordinate-wise relaxation (or method of coordinate-wise descent) with reduce the multidimensional optimization problem to one-dimensional one and use of simple iteration method within solve cycle with step-by-step procedure for improvement solutions according to the heat production output by all the sources.

\subsection{Technique for the Effectiveness Assessment of New Heat Consumer Connection Based on Local Effective Heat Supply Radius}

The LHSR represents the maximum length of a heat network section between a connection point and a consumer, whose construction and operation does not lead to an increase in the specific costs in the system. In doing so, the capital investment in the construction of a new 
heat network section and its operating costs are taken into account. Indices and criteria characterizing the effectiveness of consumer connection and in fact limiting its capabilities can include the following: a constraint on heat network losses, a constraint on the level of connection charge, a load connection effectiveness coefficient (CEC) $-k_{\mathrm{ef}}$. CEC represents a relative value determined as a ratio of heat load of an applicant to the length of a new branch and linear load density of the entire heating system from the heat source to be connected to a new consumer, considering the length of the whole heat network:

$$
k_{\mathrm{ef}}=\varepsilon Q_{j} \tau_{0} /\left(l_{j} q_{L}\right)
$$

Index $q_{L}$ is a ratio of heat load connected to a heat source $i$ to the total length of heat transmission networks at boundaries of $\operatorname{EHSR}\left(L_{\mathrm{ef}}, \mathrm{m}\right)$ :

$$
q_{L}=Q_{i} \tau_{0} / L_{\mathrm{ef}}
$$

With the value $k_{\text {ef }}$ below 1 the connection is considered to be ineffective. Consequently, the maximum (at $k_{\mathrm{ef}}=1$ ) connection distance for consumer $j$ is determined by the expression:

$$
l_{j \max }=\varepsilon Q_{j} \tau_{0} / q_{L}
$$

The minimum necessary load level (at $k_{\text {ef }}=1$ ) of consumer $j$ for its connection at a fixed point at some distance $l_{j}$ from the heat network is calculated by the expression:

$$
Q_{\text {min }}=q_{L} l_{j} /\left(\varepsilon \tau_{0}\right)
$$

To make a decision on whether or not the new consumer connection to the heating system is economically viable, we developed an algorithm consisting of the following stages.

- Collect and process the initial information;

- Determine the boundaries of EHSR for the heat network (a set of points on the network, «cutting out» a part for which the heat cost exceeds an average cost in DHS). The radius is determined by model presented in the part 2.1 ;

- Calculate the maximum length of heat pipelines from the connection point on the existing heat network to a new consumer by Eq. 20;

- Determine consumer charge for connection to DHS according to the following rules:

- If a point of new consumer connection to the existing network lies in the zone of EHSR and the length of a new heat pipeline does not exceed the maximum length obtained in step 3, the connection charge corresponds to an established level approved by the government,

- If a point of new consumer connection to the existing network lies in the zone of EHSR, but the length of a new heat pipeline exceeds the maximum length obtained in step 3, the connection charge is agreed individually and normally exceeds the established level approved by the government. If the consumer connection leads to a rise in specific heat production and transportation costs throughout the system, then an individual heat tariff is established for the consumer, which allows compensation for the increase in the costs,

- If a point of new consumer connection to the existing network lies beyond the zone 
of EHSR, the connection charge is agreed individually, and an individual heat tariff is considered to compensate for an increase in specific heat production and transportation costs.

\section{Case Study}

A scheme of the DHS on Irkutsk city map is presented in the Fig. 1. The heat transmission and distribution heat network in this large system have two pipes. The supply-return temperature of heat supply is $150 / 70{ }^{\circ} \mathrm{C}$. The pipelines are laid above ground on low and high support beams, and underground in no-passage and passage ducts. The total length of heat network from the Novo-Irkutskaya combined heat and power plants (NICHPP) makes up $474.3 \mathrm{~km}$, including $112.9 \mathrm{~km}$ of transmission pipelines (TP). The installed electric capacity of the NICHPP is $708 \mathrm{MW}$, the installed heat capacity is $2010 \mathrm{MW}$. The service area of this plant covers three city districts. All of them are either completely or partially supplied with heat from this heat source along three TP: TP-1, TP-2, and TP-4. TP-3 supplies heat to consumers in suburban settlement.

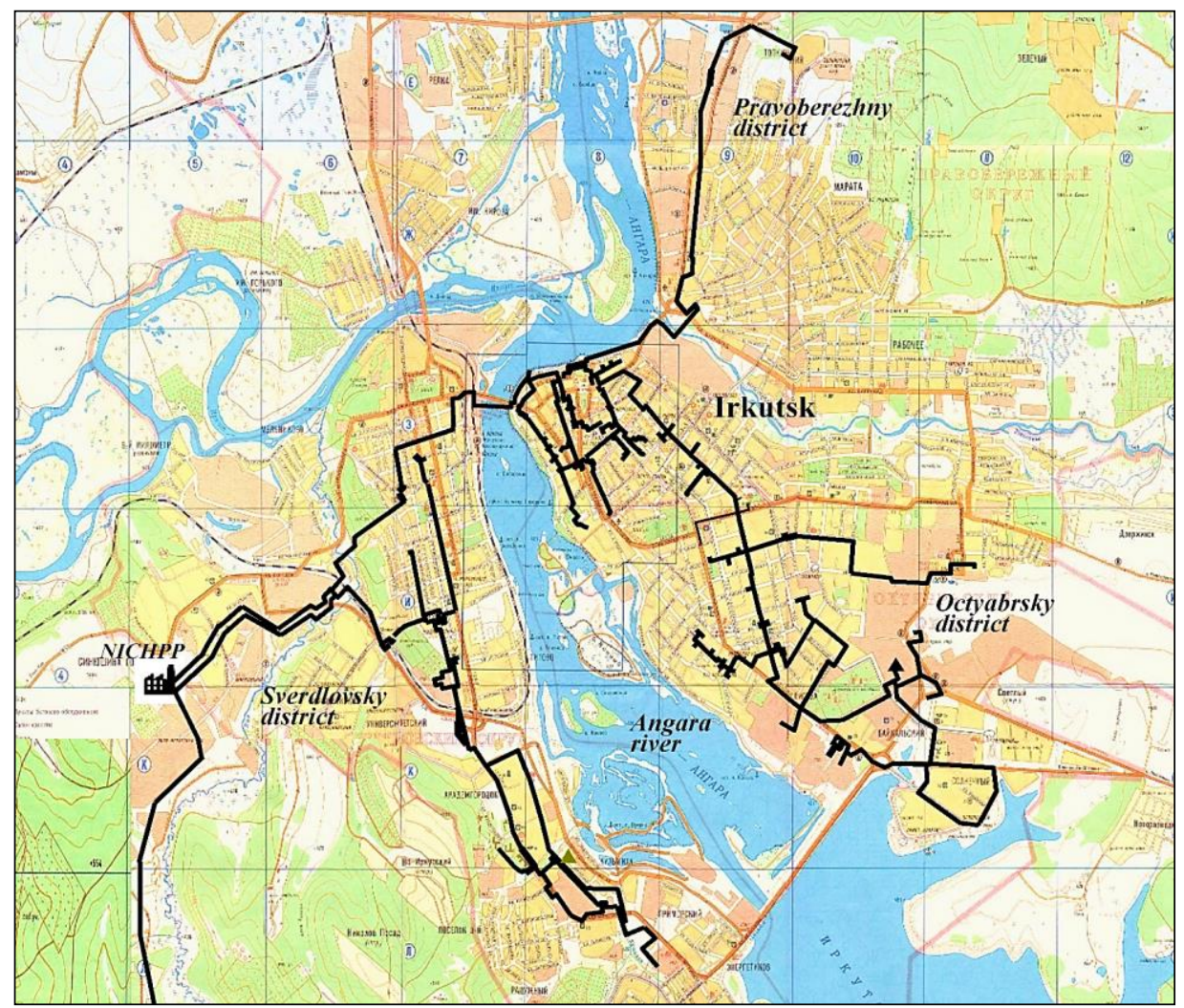

Fig. 1. DHS of Irkutsk on the city map.

According to methods presented in the part 2.1, EHSR was calculated for the NICHPP in Irkutsk. The GAMS (General Algebraic Modeling Systems) software package is used as a 
solver. An aggregate scheme of the considered heating system with decisions on EHSR is presented in the Fig. 2. Its values for the NICHPP (disregarding reliability requirements) along the transmission pipelines and their branches are limited by nodes highlighted in red in the Fig. 2. The values of the radius vary from $2 \mathrm{~km}$ (the least distance between the consumer and source) to $15.5 \mathrm{~km}$ in the direction of pumping station PS 4-7.

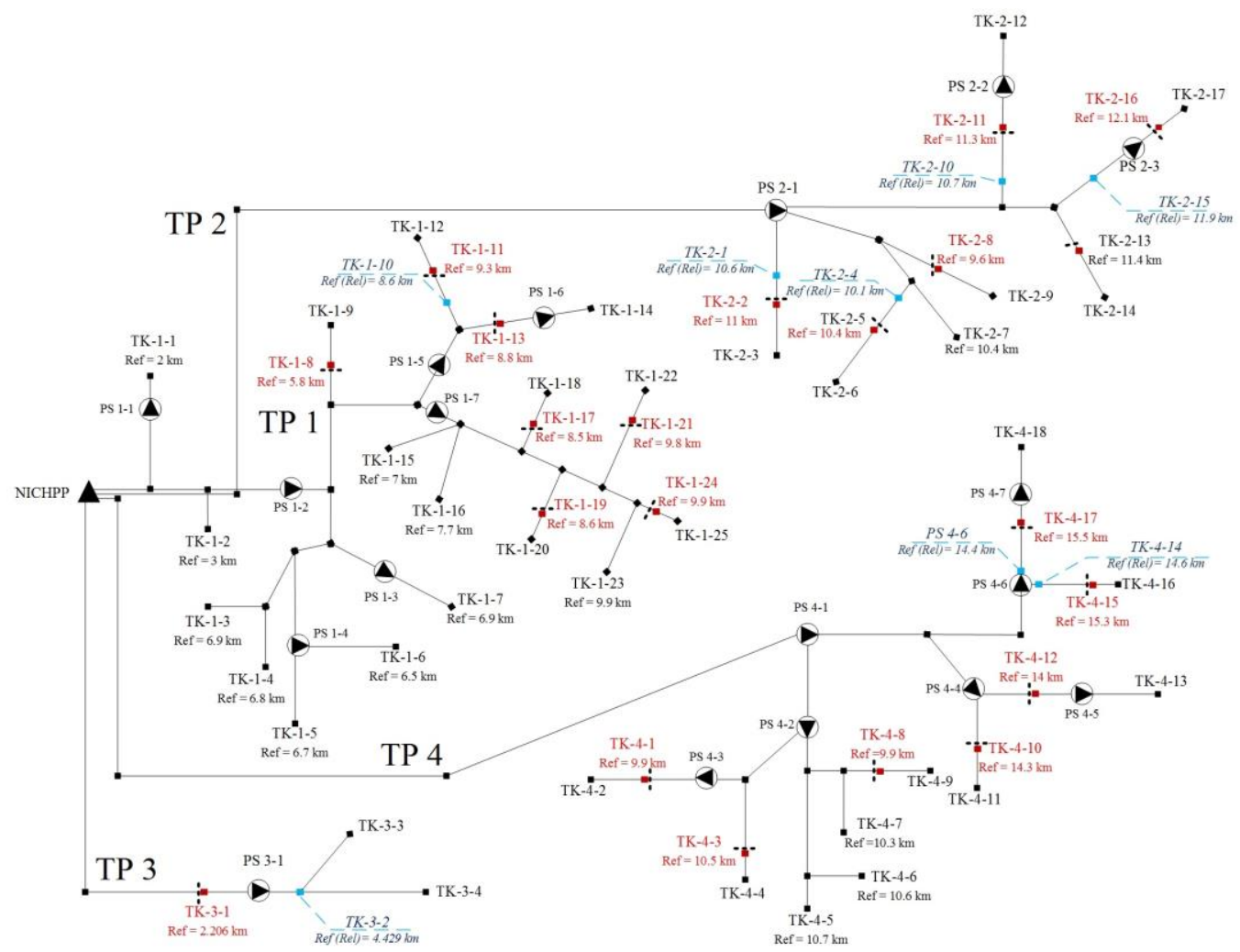

Fig. 2. Aggregate scheme of the DHS (NICHPP) with decisions on EHSR.

An analysis of heating system reliability shows that the standard values of availability factor and probability of failure-free operation, set according to [51], [52], are not met for some nodes that belong to the zones of EHSR. According to the reliability indices obtained, we adjusted EHSR in the considered system. In the Fig. 2, the boundaries of EHSR, considering reliability, are shown in blue color and dashed lines. Thus, the maximum EHSR for the NICHPP, considering the reliability requirements, will decline from $15.5 \mathrm{~km}$ to $14.6 \mathrm{~km}$ and the total length of the heat transmission networks in the zone of EHSR will shrink by $4.2 \mathrm{~km}$ and make up $67.7 \mathrm{~km}$. According to the obtained results, considering reliability requirements, the zone of EHSR embraces $284.3 \mathrm{~km}$ of heat network out of $474.3 \mathrm{~km}$, i.e. $40 \%$ of the networks are beyond EHSR zone. Connection of new consumers (according to the technique presented in the part 2) within the boundaries of EHSR with the existing technical feasibility does not lead to an increase in the heat cost.

Specific heat cost for the longest branches of TP and average specific heat cost for the system are presented in the Fig. 3. Correlation between the heat load and a material 
characteristic of the heat network has a significant influence on the specific heat cost for each node. The greater the specific material characteristic of the heat network (per heat load unit), the higher the specific heat cost and vice versa. All network sections have different specific material characteristic and EHSR depends on it.

The maximum length of a heat pipeline from the point of new consumer connection to the existing heat network is calculated according to the technique proposed in the part 2.2. Fig. 4 presents the maximum length of the pipeline from the point of connection to the existing heat network to a new consumer, which was calculated according to Eq. 20. The obtained values are recommended to be updated annually or when EHSR changes due to a considerable change in the connected heat load and total length of the heat network. Fig. 4 shows that the connection of a new consumer is justified if a heat pipeline is constructed on the basis of $156 \mathrm{~m}$ per $1 \mathrm{MW}$ at a supply/return temperature of $150 / 70{ }^{\circ} \mathrm{C}$ (or at a temperature difference in supply and return pipelines equal to $80^{\circ} \mathrm{C}$ ). A lower temperature difference in supply and return pipelines in the network section is characterized by an uplift in capital and operating costs. Therefore, the maximum length of the heat pipeline declines.

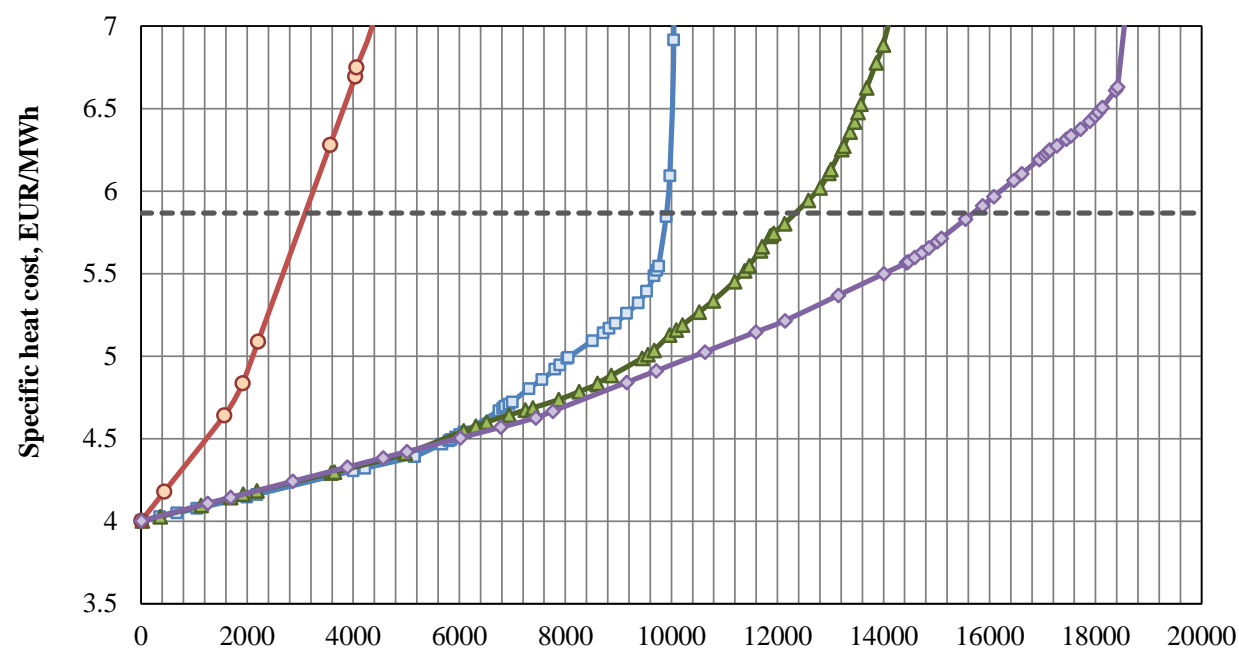

Distance from heat source to consumer, $\mathbf{m}$

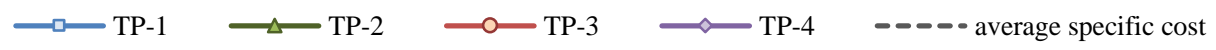

Fig. 3. Specific heat cost for the longest branches of transmission pipelines (TP) of the DHS of Irkutsk city on based NICHPP: crossing of line with average level (dashed line) corresponds to decision on EHSR. 


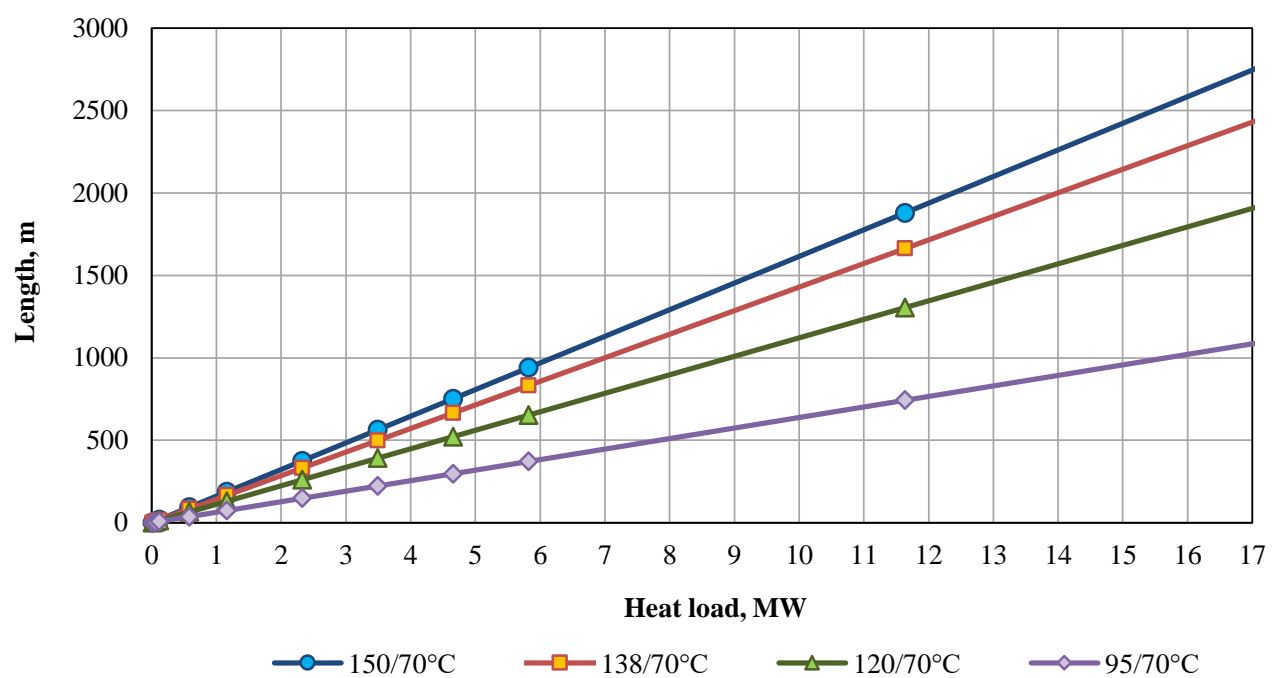

Fig. 4. The maximum length of a heat pipeline from the point of new consumer connection to the transmission pipeline of DHS based on NICHPP.

In the event that the applicant is located in the zone of effective heat supply radius and wants to connect a $1.16 \mathrm{MW}(1 \mathrm{Gcal} / \mathrm{h})$ load to the heating system at a supply/return temperature of $120 / 70{ }^{\circ} \mathrm{C}$, DHS company, based on connection effectiveness coefficient, assesses the connection feasibility, and makes pipeline routing from a connection point to a consumer. If the obtained value is either above or equal to 1 , the connection of this consumer will not increase the specific costs in the system. However, if CEC is below 1 the construction and operation of a new heat network section will cause non-standard costs and consequently a rise in the connection charge and heat tariffs. Therefore, the connection charge should be agreed individually according to the real costs of the network construction. Moreover, the consumer must compensate for the non-standard annual operating costs of heat network section.

\section{Conclusions}

The paper proposes a technique for the calculation of EHSR for a heat source in the DHS. The radius is determined as a set of nodes in a heat network scheme. The cost of heat production and transportation at these nodes does not exceed its average values throughout the considered DHS. The considered problem is formulated as determine to maximum effective heat supply radius at minimum cost price on production and distribution thermal energy in DHS taking into account requirements to reliability heat supply to consumers. Proposed methods are universal for any type of DHS. It takes into account individual features of territories and can be successfully applied in design of heat supply schemes.

Connection of new consumers within the boundaries of EHSR, considering reliability requirements, will restrain the cost rise in the DHS, decrease heat losses and ensure the required level of system reliability. Heat supply to consumers situated beyond the zone of EHSR requires a plan for the construction of a new heat source. At the same time, the boundaries of the expansion zone of an optimal DHS (i.e. connection of new consumers) cannot be determined by a single value of EHSR, since the heat loads are non-uniformly 
distributed throughout the system. It seems sensible to resolve the question of consumer connection, taking into account both EHSR and the distance between the consumer and connection point to the heat network in the zone of radius (LHSR).

We propose a technique to assess the economic viability of new connections. This technique can be used by DHS company and regulators to assess the cost-effectiveness of the connection, and the costs required for each new consumer. In the first stage, we estimate whether or not the section of the transmission pipeline where the consumer connection is planned belongs to the zone of EHSR. In the second stage, we calculate the maximum heat pipeline length from the connection point to a new consumer (LHSR). The consumers located beyond the zone of EHSR or within this zone but beyond the limits of admissible distance from the connection point, should be connected individually and under an individual tariff, provided there is an available heat capacity of the heat source and available transmission capacity of heat network.

\section{ACKNOWLEDGEMENT}

Methodology part of the work was developed with the support of the Russian Foundation for Basic Research (project 1748-380010 r_a); practical researches and calculations (Case Study) was performed at Melentiev Energy Systems Institute SB RAS under the support of Russian Science Foundation (Grant No. 17-19-01209).

\section{REFERENCES}

[1] Nuorkivi A. District heating and cooling policies worldwide. In: Wiltshire R. (Ed.), Advanced District Heating and Cooling (DHC) Systems. Woodhead Publishing is an imprint of Elsevier, 2016.

[2] Gong M., Werner S. Mapping energy and exergy flows of district heating in Sweden. Energy Procedia 2017:116:119-127. doi:10.1016/j.egypro.2017.05.060

[3] Werner S. International review of district heating and cooling. Energy 2017:137:617-631. doi:10.1016/j.energy.2017.04.045

[4] Levin L., Beneson E., et al. Scientific and Technical Progress in District Heating and Cogeneration. In: Rudenko, Y. (Ed.), Soviet Technology Reviews Book Series. Section A. Energy Reviews. Taylor \& Francis, UK, 1990.

[5] Lund H., Werner S., Wiltshire R., et al. 4th Generation District Heating (4GDH): Integrating smart thermal grids into future sustainable energy systems. Energy 2014:68:1-11. doi:10.1016/j.energy.2014.02.089

[6] Vigants E., Prodanuks, Vigants G., Veidenbergs I., Blumberga D. Modelling of Technological Solutions to 4th Generation DH Systems. Environmental and Climate Technologies 2017:20(1):5-23. doi:10.1515/rtuect-2017-0007

[7] Lund H., Duic N., Ostergaard P., Mathiesen B. Smart energy systems and 4th generation district heating. Energy 2016:110:1-4.doi: 10.1016/j.energy.2016.07.105

[8] Oregi X., Hermoso N., Arrizabalaga E., Mabe L., Munoz I. Sensitivity assessment of a district energy assessment characterisation model based on cadastral data. Energy Procedia 2018:147:181-188. doi:10.1016/j.egypro.2018.07.053

[9] Locmelis K., Blumberga D., Bariss U. Energy efficiency in large industrial plants. Legislative aspects. Energy Procedia 2018:147:202-206. doi:10.1016/j.egypro.2018.07.058

[10] Locmelis K., Blumberga A., Bariss U., Blumberga D. Energy policy for energy intensive manufacturing companies and its impact on energy efficiency improvements. System dynamics approach. Energy Procedia 2017:128:10-16. doi:10.1016/j.egypro.2017.09.005

[11] Polikarpova I., Rosa M. Energy reduction potential of the district heating company introducing energy management systems. Energy Procedia 2017:128:66-71. doi:10.1016/j.egypro.2017.09.016

[12] Zinko H., Bohm B., Sipila K., Rama M. District heating distribution in areas with low heat demand density. In: Zinko H. (Ed.), Report from IEA Implementing Agreement on District Heating and Cooling, Including the Integration of CHP, Annex VIII 2008:8DHC-08-03.

[13] Latosov E., Volkova A., Siirde A., Kurnitski J., Thalfeldt M. Methodological Approach to Determining the Effect of Parallel Energy Consumption on District Heating System. Environmental and Climate Technologies 2017:19(1):5-14. doi:10.1515/rtuect-2017-0001

[14] Latosov E., Volkova A., Siirde A., Thalfeldt M., Kurnitski J. The Impact of Parallel Energy Consumption on the District Heating Networks. Environmental and Climate Technologies 2019:23(1):1-13. doi:10.2478/rtuect-2019-0001 
[15] Christensen B., Jensen-Butler C. Energy and urban structure: Heat planning in Denmark. Progress in Planning 1982:18(2):57-132. doi:10.1016/0305-9006(82)90008-3

[16] Kristensen P., Sletbjerg M. Energydata - planning and analysis in a GIS. Proceedings of the ESRI User Conference. Munich: 1998.

[17] Moller B. A heat atlas for demand and supply management in Denmark. Management of Environmental Quality: An International Journal 2008:19(4):467-479. doi:10.1108/14777830810878650

[18] Persson U., Werner S. Heat distribution and the future competitiveness of district heating. Applied Energy 2011:88(3):568-576. doi:10.1016/j.apenergy.2010.09.020

[19] Werner S. District heating and cooling in Sweden. Energy 2017:126:419-29. doi:10.1016/j.energy.2017.03.052

[20] Connolly D., Lund H., Mathiesen B., et al. Heat Roadmap Europe: Combining district heating with heat savings to decarbonise the EU energy system. Energy Policy 2014:65:475-489. doi:10.1016/j.enpol.2013.10.035

[21] Connolly D., Mathiesen B., Ostergaard P., et al. Heat Roadmap Europe: Second Pre-Study, Aalborg University, Halmstad University, Ecofys Germany GmbH, PlanEnergi and Euroheat \& Power, 2013.

[22] HRE4. Heat Roadmap Europe 4. Heating and Cooling, Facts and Figures [Online]. [Accessed 10.02.2019]. Available: http://www.heatroadmap.eu/

[23] Persson U., Moller B., Werner S. Heat Roadmap Europe: Identifying strategic heat synergy regions. Energy Policy 2014:74:663-681. doi:10.1016/j.enpol.2014.07.015

[24] Dalla-Rosa A., Li H., Svendsen S. Method for optimal design of pipes for low-energy district heating, with focus on heat losses. Energy 2011:36(5):2407-2418. doi:10.1016/j.energy.2011.01.024

[25] Tol H., Svendsen S. Improving the dimensioning of piping networks and network layouts in low-energy district heating systems connected to low-energy buildings: A case study in Roskilde, Denmark. Energy 2012:38:276-290. doi:10.1016/j.energy.2011.12.002

[26] Volkova A., Mashatin V., Hlebnikov A., Andres S. Methodology for the Improvement of Large District Heating Networks. Environmental and Climate Technologies 2012:10(1):39-45. doi:10.2478/v10145-012-0009-7

[27] Bolonina A., Bolonins G., Blumberga D. Analysis of the Impact of Decreasing District Heating Supply Temperature on Combined Heat and Power Plant Operation. Environmental and Climate Technologies 2014:14(1):41-46. doi:10.1515/rtuect-2014-0013

[28] Schmidt D., et al. Low temperature district heating for future energy systems. Energy Procedia 2017:116:26-38. doi:10.1016/j.egypro.2017.05.052

[29] Schuchardt (neé Bestrzynski) G. K. Integration of decentralized thermal storages within district heating networks. Environmental and Climate Technologies 2016:18(1):5-16. doi:10.1515/rtuect-2016-0009

[30] Persson U., Werner S. Effective width - the relative demand for district heating pipe lengths in city areas. In: Proceedings of The 12th International Symposium on District Heating and Cooling. Tallinn, Estonia: 2010:128-131.

[31] BSREC. District Heating and Cooling, Combined Heat and Power and Renewable Energy Sources. The Baltic Sea Region Energy Cooperation, 2014. [Online]. [Accessed 10.02.2019]. Available: http://basrec.net/wp-content/uploads/2014/06/Appendix\%20-\%20country\%20survey.pdf

[32] Patronen J., Kaura E., Torvestad C. Nordic heating and cooling. Nordic approach to EU's Heating and Cooling Strategy. Nordic Council of Ministers, 2017. [Online]. [Accessed 10.02.2019]. doi: 10.6027/TN2017-532

[33] DEA. District Heating - Danish and Chinese Experience. Danish Energy Agency, Danish Board of District Heating; 2017. [Online]. [Accessed 10.02.2019]. Available: https://ens.dk/sites/ens.dk/files/energistyrelsen/ Nyheder/district_heating_danish-chinese_experiences.pdf

[34] Zhang L., Gudmundsson O., Li H., Svendsen S. Comparison of District Heating Systems Used in China and Denmark. International Journal of Sustainable and Green Energy 2015:4(3):102-116.

[35] Pakere I., Ziemele J., Blumberga D. DH company in prosumers role. Energy Procedia 2017:128:234-239. doi:10.1016/j.egypro.2017.09.061

[36] Postnikov I., Stennikov V., Penkovskii A. Prosumer in the District Heating Systems: Operating and Reliability Modeling. Energy Procedia 2019:158:2530-2535. doi:10.1016/j.egypro.2019.01.411

[37] Chicherin S. Low-temperature district heating distributed from transmission-distribution junctions to users: energy and environmental modelling. Energy Procedia 2018:147:382-389. doi:10.1016/j.egypro.2018.07.107

[38] Brailov V., Kuznetsov Y., Khrilev L. Determining the economic efficiency of combined and separate schemes of power supply on the basis of nuclear and fossil fuel. Thermal Engineering 2011:58(12):1033-1042. doi:10.1134/S0040601511120056

[39] Khrilev L., Smirnov I. Socio-Economic Principles and Lines of Development of District Heating. Thermal Engineering 2005:52(2):93-102.

[40] Yakimov L. Maximum radius of district heating action. Heat and power 1931:9:8-10.

[41] Stennikov V., Iakimetc E. Optimal planning of heat supply systems in urban areas. Energy 2016:110:157-165. doi:10.1016/j.energy.2016.02.060

[42] Filippov S. P. Development of Centralized District Heating in Russia. Thermal Engineering 2009:56(12):985-997. doi:10.1134/S0040601509120015

[43] Papushkin V. Heat supply radius. The well-forgotten old. News of heat supply 2010:9:44-9. 
[44] Semenov V., Razorenov R. Express-analysis of relationship between heat transportation effectiveness and remoteness of consumers. News of heat supply 2006:6:36-38.

[45] Stennikov V., Mednikova E. Analysis of Trends in the Development of Cities' Heat Supply Systems. Thermal Engineering 2016:63(9):657-665. doi:10.1134/S0040601516090068

[46] Ershova M. Introduction into a bi-level programming. Manual. Irkutsk: ISU, 2006.

[47] Bard J. F. Practical Bilevel Optimization. Springer Science + Business Media Dordrecht, 1998. doi:10.1007/978-14757-2836-1

[48] Dempe S. Foundations of Bilevel Programming. Dordrecht, Netherlands: Kluwer Academic Publishers, 2002.

[49] Merenkov A., Khasilev V. Theory of hydraulic circuits. Moscow: Nauka, 1985.

[50] Sennova E., et al. Reliability of heat supply systems. Novosibirsk: Nauka, 2000.

[51] Stennikov V., Postnikov I. Methods for the integrated reliability analysis of heat supply. Power Technology and Engineering 2014:47(6):446-453. doi:10.1007/s10749-014-0467-0

[52] Postnikov I., Stennikov V., Mednikova E., Penkovskii A. Methodology for optimization of component reliability of heat supply systems. Applied Energy 2018:227:365-374. doi:10.1016/j.apenergy.2017.11.073 